\title{
Day to day variation in 3 orthogonal lead electrocardiogram parameters after acute myocardial infarction
}

\author{
H. T. Cawood, S. Hillis, P. W. Macfarlane, and T. D. V. Lawrie \\ From the University Department of Medical Cardiology, Royal Infirmary, Glasgow
}

Serial 3 orthogonal lead electrocardiograms were recorded on 67 patients with acute myocardial infarction. For each series of electrocardiograms, the day to day changes and the changes with respect to the initial computer measurements of selected ST-T segment amplitudes and vector orientations were investigated. The results indicated that the degree of rotation of $S T-T$ vectors, which corresponded with a report of sequential change by a panel of cardiologists, was outside the upper limit of normal day to day variation. From the results, diagnostic criteria for use in the automated detection of sequential electrocardiographic changes after myocardial infarction were established.

The evolution of ST-T changes in the 12 lead electrocardiogram after acute myocardial infarction is well known. These sequential changes are frequently of importance in confirming the diagnosis, especially in doubtful cases. Similar ST-T changes can be demonstrated in the 3 orthogonal lead electrocardiogram.

While cardiologists interpret sequential ST-T changes on a subjective basis, precise criteria must be formulated if the detection of these changes is to be carried out by digital computer. To this end, a study was initially made of the day to day and beat to beat variation of normal 3 orthogonal lead electrocardiograms so that normal ranges of variation could be determined (Cawood et al., 1974). The present study was then undertaken to establish criteria for detecting serial ST-T changes after acute myocardial infarction for use by a digital computer programme for electrocardiogram interpretation.

\section{Subjects and methods}

A total of 67 patients, consisting of 52 men ranging in age from 37 to 74 years (mean age $53 \pm 9$ ) and 15 women ranging in age from 49 to $9 \mathrm{I}$ years (mean age $67 \pm \mathrm{II}$ ), was selected for this study. On the basis of clinical, biochemical, and electrocardiographic evidence, each patient was diagnosed as having sustained an acute myocardial infarction. None of their electrocardiograms showed conduction abnormalities of the complete bundle-branch block type.

Received 25 April 1974.
On each patient, 3 and 12 lead electrocardiograms were recorded on several occasions during their hospital stay. The number of cardiograms recorded varied according to the length of stay of each patient but was at least three. Different cardiographers recorded the serial electrocardiograms using unmarked electrode positions.

A panel of three experienced cardiologists reported the I2 lead electrocardiograms while the 3 lead electrocardiograms were interpreted by computer using a programme described elsewhere (Macfarlane, I97I; Macfarlane et al., 1972). The provisional diagnosis of myocardial infarction was made by routine hospital procedures involving many physicians so that strict criteria for the 12 lead electrocardiographic interpretation of myocardial infarction could not be used at that stage. However, the cardiologists who subsequently reviewed the 12 lead electrocardiograms used conventional criteria for confirmation of the diagnosis. A complete list can be found elsewhere (Macfarlane, 1969b).

At the beginning of the study, there were no borderline values established for significant day to day changes in ST-T parameters in the 3 lead electrocardiogram. It was, therefore, of importance for the cardiologists to indicate whether or not they subjectively regarded a significant change to be present on the basis of either 3 or 12 lead electrocardiographic appearances.

The criteria used by the computer programme for the detection of myocardial infarction using the modified axial 3 orthogonal lead electrocardiogram system (Macfarlane, 1969a) were as follows (in abbreviated form).

i) Inferior myocardial infarction

$(\mathrm{Q} / \mathrm{R})_{\mathrm{Y}}>\mathrm{I} / 3$ and

$180^{\circ}<0.03 \mathrm{sec} \mathrm{QRS}_{\mathrm{F}}$ vector $<5^{\circ}$ 
ii) Anterolateral myocardial infarction

$(\mathrm{Q} / \mathrm{R})_{\mathrm{X}}>\mathrm{I} / 3$ and $90^{\circ}<0.03 \mathrm{sec} \mathrm{QRS}_{\mathrm{T}}$ vector $<290^{\circ}$

iii) Anteroseptal myocardial infarction $\left(\mathrm{Q}_{\mathrm{z}}>0.03 \mathrm{sec}\right.$ and $\left.\mathrm{Q}_{\mathrm{z}}>0.1 \mathrm{mV}\right)$ or $\left((\mathrm{R} / \mathrm{S})_{\mathrm{z}}<0 . \mathrm{I}\right.$ and $\mathrm{R}_{\mathrm{z}}<0.1 \mathrm{I} \mathrm{mV}$ and $180^{\circ}<0.03 \mathrm{sec} \mathrm{QRS}_{\mathrm{T}}<330^{\circ}$ )

$\mathrm{QRS}_{\mathrm{F}}$ and $\mathrm{QRS} \mathrm{S}_{\mathrm{T}}$ denote the projection of the $\mathrm{QRS}$ vector onto the frontal and transverse planes, respectively. The $0.03 \mathrm{sec} Q R S$ vector is the vector recorded $0.03 \mathrm{sec}$ after $\mathrm{QRS}$ onset. The anteroseptal lead $\mathrm{Z}$ is directed anteriorly positively so that a $Q$ wave in the anteroseptal lead (denoted $\mathrm{Q}_{\mathrm{z}}$ ) compares with a $\mathrm{Q}$ wave in V2. Similarly a $Q$ wave in the inferior lead $Y$ (denoted $Q_{Y}$ ) can be compared to a $Q$ wave in aVF, and a $Q$ wave in the anterolateral lead $X$ (denoted $Q_{X}$ ) can be compared to a $Q$ wave in lead $I$.

ST elevation of more than $0.06 \mathrm{mV}$ in the inferior or anterolateral leads, or more than $0.08 \mathrm{mV}$ in the anteroseptal lead, was used as an indication that the infarct was acute.

Widespread myocardial infarction was diagnosed when the above criteria were met in each lead. Anterior myocardial infarction was reported when abnormalities in both the anteroseptal and anterolateral leads were present.

For each set of serial recordings, the variation in measurement of the following ST-T wave parameters was studied.

i) The amplitude of the $5 / 8,6 / 8$ time normalized ST- $T$ vector components in leads $\mathrm{X}$ and/or $\mathrm{Y}$ and/or $\mathrm{Z}$.

ii) The maximum $T$ wave amplitude in leads $X$ and/or $Y$ and/or $Z$.

iii) The orientation of the projection of maximum spatial $T$ vector, the $5 / 8$ and $6 / 8$ ST-T time normalized vectors onto the frontal $(\mathrm{XY})$ and/or right sagittal (ZY) and/or transverse (XZ) planes.

The variation of $Q R S$ components is not included in the present report.

For each patient's series of electrocardiograms the variation in the $T$ wave scalar and vector components was calculated for the leads and reference planes appropriate to the type of infarction detected, e.g. for inferior myocardial infarction, the variation in ST-T segment amplitude was computed for the inferior lead $\mathrm{Y}$ alone and the change in $T$ vector orientation was measured using the projection of the ST-T vectors onto the frontal plane. Similarly for anteroseptal myocardial infarction, the $T$ wave amplitude in lead $Z$ and the ST- $T$ vector orientations in the transverse plane were studied. The latter were also used in anterior myocardial infarction.

To determine the day to day variation in electrocardiographic parameters after acute myocardial infarction, average measurements for individual electrocardiograms were first computed by a technique in which each electrocardiogram was interpreted by the computer three times, with a different complex being analysed on each occasion (Cawood et al., 1974). Thus for each individual electrocardiogram, the mean value of a set of three measurements was obtained for each parameter. Thereafter day to day changes were calculated using the mean value for each parameter calculated on each day. In addition, the changes of the second and subsequent electrocardiograms with respect to the first electrocardiogram were also studied.

Means, standard deviations, and total ranges of the day to day variation and the variation with respect to the initial electrocardiogram were calculated. The direction of the change was also taken into account, e.g. increased and decreased amplitude changes were treated separately as were clockwise and counterclockwise rotations of the selected vectors.

\section{Results}

Care must be taken with the mathematical treatment of angular data where the mean of several values has to be calculated. Several authors (e.g. Downs et al., I966; Downs, Liebman, and MacKay, I97I) have discussed statistical techniques for dealing with this problem. In the present study, however, the analysis has been more concerned with the change in vector angle than any other statistical measurement, though this too can present difficulties, e.g. if a vector swings initially counterclockwise through $45^{\circ}$ then $120^{\circ}, 160^{\circ}$, and finally $185^{\circ}$ (see Fig. I), it might be thought that a result indicating a counterclockwise swing of $185^{\circ}$ was wrong since it can be seen from the diagram (Fig. I) that this rotation is equivalent to a clockwise change of $175^{\circ}$. This illustrates the problem in presenting data on vector rotation, and was partly the reason why the vector rotations have been divided into two groups - those in a clockwise direction and those in a counterclockwise direction.

The mean changes together with total ranges in selected scalar amplitude and vector orientations are

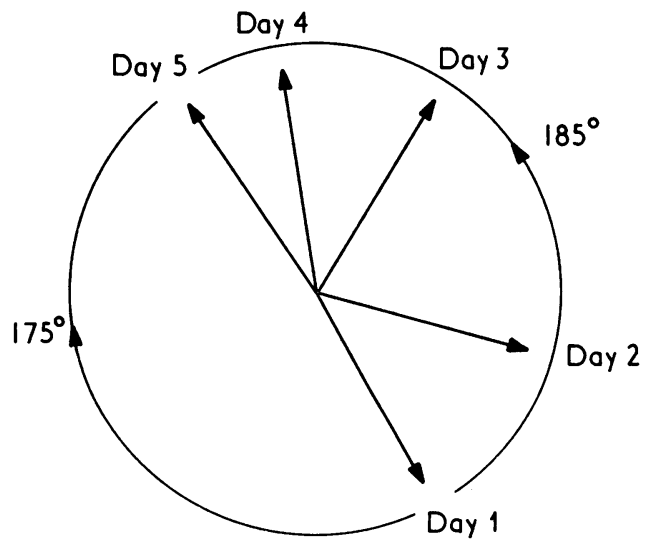

FIG. I An illustration of vector rotation through $185^{\circ}$ in a counterclockwise fashion. Consideration of only the first and last measurements would have led to a result of $175^{\circ}$ change in a clockwise manner. 
presented in Tables I-4. Only those vectors ultimately selected for use in the formulation of criteria are shown while only the change in maximum $T$ wave amplitudes is given for brevity, since no scalar measurements proved of value as discussed below. Both the increase and decrease in amplitude changes are presented together with clockwise and counterclockwise changes in vector orientations.

\section{Widespread myocardial infarction}

The results for the six patients whose electrocardiograms showed sequential changes after widespread myocardial infarction are presented in Tables IA and IB. Of importance is the fact that the mean changes in the maximum $T$ vector orientations are much greater than the upper limit of normal variation presented separately (Cawood et al., 1974). The predominant direction of rotation was clockwise in both frontal and transverse planes.

\section{Anterior myocardial infarction}

The results for the 14 patients with anterior myocardial infarction are presented in Tables $2 \mathrm{~A}$ and $2 \mathrm{~B}$. The mean changes in vector angles are considerably outside the normal ranges as are the mean decreases in $T$ wave amplitudes with respect to the initial measurements.

\section{Inferior myocardial infarction}

The results for the 2 I patients with sequential electrocardiographic changes after inferior myocardial infarction are presented in Tables $3 \mathrm{~A}$ and $3 \mathbf{B}$. As expected there was a considerable swing of the $\mathrm{T}$ vector in the frontal plane and a decrease (i.e. inversion) in $\mathrm{T}$ wave amplitude after the acute stage of the illness.

\section{Anteroseptal myocardial infarction}

Tables $4 \mathrm{~A}$ and $4 \mathrm{~B}$ show the changes in selected ST- $T$ parameters in the anteroseptal lead and transverse plane for the II patients with anteroseptal myocardial infarction. On occasions, the mean day to day change is within normal limits whereas the mean change with respect to the initial measurement is outside the upper limit of normal.

\section{Serial electrocardiograms without sequential changes}

There were 15 patients in this study whose serial electrocardiograms did not show any sequential

TABLE IA Widespread myocardial infarction (with respect to day I): mean \pm standard deviation together with range of variation with respect to initial measurement of selected $S T-T$ vector angles and scalar amplitudes

\begin{tabular}{|c|c|c|c|c|c|c|c|c|}
\hline & $\operatorname{Max} T_{F}$ & $\operatorname{Max} T_{T}$ & $6 / 8 S T-T_{F}$ & $6 / 8 S T-T_{T}$ & & $T_{X}$ & $T_{Y}$ & $T_{z}$ \\
\hline $\begin{array}{l}\text { Clockwise } \\
\text { rotation }\left({ }^{\circ}\right)\end{array}$ & $\begin{array}{c}\text { II } 5 \pm 66 \\
\text { I5 } \rightarrow \text { I95 }\end{array}$ & $\begin{array}{r}106 \pm 74 \\
6 \rightarrow 177\end{array}$ & $\begin{array}{l}85 \pm 29 \\
31 \rightarrow 150\end{array}$ & $\begin{array}{l}76 \pm 24 \\
55 \rightarrow 112\end{array}$ & $\begin{array}{l}\text { Increased } \\
\text { amplitude } \\
(\mathrm{mV})\end{array}$ & $\begin{array}{l}0.14 \pm 0.06 \\
0.05 \rightarrow 0.21\end{array}$ & $\begin{array}{l}0.13 \pm 0.09 \\
0.02 \rightarrow 0.22\end{array}$ & $\begin{array}{l}0.06 \pm 0.02 \\
0.04 \rightarrow 0.08\end{array}$ \\
\hline $\begin{array}{l}\text { Counter- } \\
\text { clockwise } \\
\text { rotation }\left({ }^{\circ}\right)\end{array}$ & $\begin{array}{l}36 \pm 17 \\
12 \rightarrow 50\end{array}$ & $\begin{array}{l}36 \pm 3 \\
33 \rightarrow 39\end{array}$ & $\begin{array}{r}36 \pm 26 \\
6 \rightarrow 56\end{array}$ & $\begin{array}{l}7 \mathrm{I} \pm 45 \\
\mathrm{I} \rightarrow \mathrm{I} 5 \mathrm{I}\end{array}$ & $\begin{array}{l}\text { Decreased } \\
\text { amplitude } \\
\text { (mV) }\end{array}$ & $\begin{array}{l}0.27 \pm 0.22 \\
0.02 \rightarrow 0.64\end{array}$ & $\begin{array}{l}0.29 \pm 0.17 \\
0.01 \rightarrow 0.53\end{array}$ & $\begin{array}{l}0.34 \pm 0.30 \\
0.03 \rightarrow 0.86\end{array}$ \\
\hline
\end{tabular}

Note: $\mathrm{T}_{\mathrm{F}}, \mathrm{T}_{\mathrm{T}}$ denote the projection of the maximum $\mathrm{T}$ vector onto the frontal and transverse planes, respectively, whereas $T_{X}, T_{Y}$, and $T_{Z}$ denote the maximum $T$ wave amplitude in leads $X, Y$, and $Z$, respectively. Similar terminology is used for the 6/8 ST-T time normalized components.

TABLE IB Widespread myocardial infarction (day to day): mean \pm standard deviation together with complete range of day to day variations of selected $S T-T$ vector angles and scalar amplitudes

\begin{tabular}{|c|c|c|c|c|c|c|c|c|}
\hline & $\operatorname{Max} T_{F}$ & $\operatorname{Max} T_{T}$ & $6 / 8 S T-T_{F}$ & $6 / 8 S T-T_{T}$ & & $T_{X}$ & $T_{Y}$ & $T_{z}$ \\
\hline $\begin{array}{l}\text { Clockwise } \\
\text { rotation }\left({ }^{\circ}\right)\end{array}$ & $\begin{array}{c}65 \pm 67 \\
1 \rightarrow 170\end{array}$ & $\begin{array}{l}58 \pm 68 \\
3 \rightarrow 165\end{array}$ & $\begin{array}{c}52 \pm 48 \\
0 \rightarrow 150\end{array}$ & $\begin{array}{c}36 \pm 32 \\
0 \rightarrow 106\end{array}$ & $\begin{array}{l}\text { Increased } \\
\text { amplitude } \\
(\mathrm{mV})\end{array}$ & $\begin{array}{l}0.18 \pm 0.09 \\
0.07 \rightarrow 0.29\end{array}$ & $\begin{array}{l}0.08 \pm 0.07 \\
0.01 \rightarrow 0.22\end{array}$ & $\begin{array}{l}0.04 \pm 0.03 \\
0.01 \rightarrow 0.08\end{array}$ \\
\hline $\begin{array}{l}\text { Counter- } \\
\text { clockwise } \\
\text { rotation }\left({ }^{\circ}\right)\end{array}$ & $\begin{array}{c}32 \pm 45 \\
I \rightarrow I I 8\end{array}$ & $\begin{array}{c}30 \pm 43 \\
3 \rightarrow 103\end{array}$ & $\begin{array}{r}3 I \pm 38 \\
2 \rightarrow 85\end{array}$ & $\begin{array}{l}56 \pm 54 \\
3 \rightarrow 151\end{array}$ & $\begin{array}{l}\text { Decreased } \\
\text { amplitude } \\
\text { (mV) }\end{array}$ & $\begin{array}{l}0.14 \pm 0.13 \\
0.01 \rightarrow 0.47\end{array}$ & $\begin{array}{l}0.20 \pm 0.17 \\
0.02 \rightarrow 0.53\end{array}$ & $\begin{array}{l}0.22 \pm 0.24 \\
0.01 \rightarrow 0.74\end{array}$ \\
\hline
\end{tabular}


change in the opinion of the panel of cardiologists who reviewed the 3 and 12 lead electrocardiograms. The details relating to these patients are not presented but further reference is made in the discussion below.

\section{Discussion}

The ranges of normal variation of selected $P, Q R S$, and ST-T segment parameters are presented in the accompanying paper (Cawood et al., 1974). While these results indicate the parameters which show the

TABLE 2A Anterior myocardial infarction (with respect to day $I$ ): mean \pm standard deviation together with complete range of day to day variations of selected $S T-T$ vector angles and scalar amplitudes

\begin{tabular}{|c|c|c|c|c|c|}
\hline & $\operatorname{Max} T_{F}$ & $6 / 8 S T-T_{T}$ & & $T_{X}$ & $T_{Z}$ \\
\hline Clockwise rotation $\left(^{\circ}\right)$ & $\begin{array}{l}98 \pm 64 \\
2 \rightarrow 173\end{array}$ & $\begin{array}{r}121 \pm 54 \\
4 \rightarrow 193\end{array}$ & Increased amplitude (mV) & $\begin{array}{l}0.09 \pm 0.05 \\
0.04 \rightarrow 0.15\end{array}$ & $\begin{array}{l}0.12 \pm 0.11 \\
0.01 \rightarrow 0.26\end{array}$ \\
\hline Counterclockwise rotation $\left({ }^{\circ}\right)$ & $\begin{aligned} & 12 \pm 6 \\
& 3 \rightarrow 20\end{aligned}$ & $\begin{array}{l}31 \pm 27 \\
1 I \rightarrow 67\end{array}$ & Decreased amplitude (mV) & $\begin{array}{l}0.48 \pm 0.30 \\
0.02 \rightarrow 1 \cdot 16\end{array}$ & $\begin{array}{l}0.21 \pm 0.19 \\
0.1 \mathrm{I} \rightarrow 0.70\end{array}$ \\
\hline
\end{tabular}

TABLE 2B Anterior myocardial infarction (day to day): mean \pm standard deviation together with complete range of day to day variations of selected $S T-T$ vector angles and scalar amplitudes

\begin{tabular}{|c|c|c|c|c|c|}
\hline & $\operatorname{Max} T_{T}$ & $6 / 8 S T-T_{T}$ & & $T_{X}$ & $T_{z}$ \\
\hline Clockwise rotation $\left({ }^{\circ}\right)$ & $\underset{0 \rightarrow 166}{59 \pm 64}$ & $\begin{array}{c}58 \pm 60 \\
0 \rightarrow 188\end{array}$ & Increased amplitude (mV) & $\begin{array}{l}0.11 \pm 0.04 \\
0.06 \rightarrow 0.16\end{array}$ & $\begin{array}{r}0.07 \pm 0.08 \\
0 \rightarrow 0.26\end{array}$ \\
\hline Counterclockwise rotation $\left({ }^{\circ}\right)$ & $\underset{I 2}{12 \pm 6}$ & $\begin{array}{r}16 \pm 14 \\
2 \rightarrow 53\end{array}$ & Decreased amplitude (mV) & $\begin{array}{l}0.26 \pm 0.25 \\
0.02 \rightarrow I \cdot 22\end{array}$ & $\begin{array}{l}0.13 \pm 0.13 \\
0.01 \rightarrow 0.49\end{array}$ \\
\hline
\end{tabular}

TABLE 3A Inferior myocardial infarction (with respect to day $I$ ): mean \pm standard deviation together with complete range of variation with respect to initial measurement of selected $S T-T$ vector angles and scalar amplitudes

\begin{tabular}{|c|c|c|c|c|}
\hline & $\operatorname{Max} T_{F}$ & $6 / 8 S T-T_{T}$ & & $T_{Y}$ \\
\hline Clockwise rotation $\left({ }^{\circ}\right)$ & $\begin{array}{c}76 \pm 73 \\
0 \rightarrow 171\end{array}$ & $\begin{array}{l}40 \pm 34 \\
I \rightarrow I I 8\end{array}$ & Increased amplitude (mV) & $\begin{array}{l}0.17 \pm 0.18 \\
0.02 \rightarrow 0.54\end{array}$ \\
\hline Counterclockwise rotation $\left({ }^{\circ}\right)$ & $\begin{array}{c}74 \pm 54 \\
I \rightarrow 184\end{array}$ & $\begin{array}{c}53 \pm 42 \\
2 \rightarrow 162\end{array}$ & Decreased amplitude (mV) & $\begin{array}{l}0.3 I \pm 0.24 \\
0.0 I \rightarrow I .03\end{array}$ \\
\hline
\end{tabular}

TABLE $3 \mathrm{~B}$ Inferior myocardial infarction (day to day): mean \pm standard deviation together with complete range of day to day variation of selected $S T-T$ vector angles and scalar amplitudes

\begin{tabular}{|c|c|c|c|c|}
\hline & $\operatorname{Max} T_{F}$ & $6 / 8 S T-T_{F}$ & & $T_{Y}$ \\
\hline Clockwise rotation $\left(^{\circ}\right)$ & $\begin{array}{c}50 \pm 66 \\
0 \rightarrow 176\end{array}$ & $\begin{array}{c}44 \pm 38 \\
0 \rightarrow 130\end{array}$ & Increased amplitude (mV) & $\begin{array}{r}0.12 \pm 0.17 \\
0 \rightarrow 0.62\end{array}$ \\
\hline Counterclockwise rotation $\left({ }^{\circ}\right)$ & $\begin{aligned} 48 & \pm 50 \\
2 & \rightarrow 167\end{aligned}$ & $\begin{array}{c}48 \pm 52 \\
I \rightarrow 185\end{array}$ & Decreased amplitude (mV) & $\begin{array}{l}0.27 \pm 0.22 \\
0.02 \rightarrow 0.89\end{array}$ \\
\hline
\end{tabular}


TABLE 4A Anteroseptal myocardial infarction (with respect to day 1 ): mean \pm standard deviation together with complete range of variation with respect to initial measurement of selected $S T-T$ vector angles and scalar amplitudes

\begin{tabular}{lcccc}
\hline & $M a x T_{T}$ & $6 / 8 S T-T_{T}$ & $T_{z}$ \\
\hline Clockwise rotation $\left(^{\circ}\right)$ & $61 \pm 46$ & $60 \pm 37$ & Increased amplitude (mV) & $0.04 \pm 0.04$ \\
& $0 \rightarrow 134$ & $4 \rightarrow 132$ & & $0.01 \rightarrow 0.12$ \\
Counterclockwise rotation $\left(^{\circ}\right)$ & $88 \pm 77$ & $42 \pm 31$ & Decreased amplitude (mV) & $0.19 \pm 0.16$ \\
& $3 \rightarrow 183$ & $8 \rightarrow 87$ & & $0.01 \rightarrow 0.51$ \\
\hline
\end{tabular}

TABLE 4B Anteroseptal myocardial infarction (day to day): mean \pm standard deviation together with complete range of day to day variations of selected $S T-T$ vector angles and scalar amplitudes

\begin{tabular}{|c|c|c|c|c|}
\hline & $\operatorname{Max} T_{T}$ & $6 / 8 S T-T_{T}$ & & $T_{z}$ \\
\hline Clockwise rotation $\left({ }^{\circ}\right)$ & $\begin{array}{c}43 \pm 43 \\
0 \rightarrow 150\end{array}$ & $\begin{aligned} 41 & \pm 36 \\
3 & \rightarrow 120\end{aligned}$ & Increased amplitude (mV) & $\begin{array}{r}0.06 \pm 0.08 \\
0 \rightarrow 0.26\end{array}$ \\
\hline Counterclockwise rotation $\left({ }^{\circ}\right)$ & $\begin{aligned} 43 & \pm 54 \\
6 & \rightarrow 177\end{aligned}$ & $\begin{array}{c}35 \pm 46 \\
2 \rightarrow 170\end{array}$ & Decreased amplitude (mV) & $\begin{array}{l}0.15 \pm 0.11 \\
0.05 \rightarrow 0.46\end{array}$ \\
\hline
\end{tabular}

least day to day and beat to beat variation, they cannot give any indication as to which parameters are the best discriminators with respect to the detection of serial changes after myocardial infarction. The results from the current study were, therefore, compared with the normal ST-T variation data in order that criteria for the detection of sequential changes after myocardial infarction could be formulated.

It was found, using the ' $t$ ' test, that the mean changes in vector orientations both with respect to initial measurements and on a day to day basis were statistically significantly different $(P<0.05)$ from the normal mean changes in almost all cases. On the other hand many of the mean changes in amplitude of scalar measurements were not significantly different from normal at the 0.05 significance level. Such results suggested that vector rather than scalar data be used to formulate criteria which must be based on a knowledge of the normal ranges and in particular the maximal variation, defined in the accompanying paper as the maximum of the normal day to day and beat to beat variation (Cawood et al., 1974).

It was found that a change (either day to day or otherwise) in maximum $T$ vector orientation outside the maximal variation in the appropriate plane was present in most patients who were regarded by the panel of cardiologists as having evidence of sequential electrocardiographic changes. In series where terminal $T$ wave changes occurred, the $6 / 8$ ST-T vector was sometimes found to rotate through a number of degrees outside the appropriate normal maximal variation and was on occasions the only indication of sequential change. This suggested that both the maximum $T$ and $6 / 8$ ST-T vector be used in the formulation of criteria for the detection of sequential changes.

Table 5 shows the proposed diagnostic criteria

TABLE 5 Proposed diagnostic criteria for detection of segmental ST-T changes in serial 3 lead electrocardiograms derived from modified axial lead system

\begin{tabular}{lllll}
\hline Location of myocardial infarction & \multicolumn{4}{l}{ Clockwise or counterclockwise rotation } \\
\cline { 2 - 5 } & $\operatorname{Max} T_{F}$ & $\operatorname{Max} T_{T}$ & $6 / 8 S T-T_{F}$ & $6 / 8 S T-T_{T}$ \\
\hline Inferior & $30^{\circ}$ & - & $70^{\circ}$ & - \\
Anteroseptal & - & $30^{\circ}$ & - & $70^{\circ}$ \\
Anterior (or anterolateral) & $30^{\circ}$ & $30^{\circ}$ & $\overline{7}$ & $70^{\circ}$ \\
Widespread & $30^{\circ}$ & $70^{\circ}$ & $70^{\circ}$ \\
\hline
\end{tabular}

Note: A change exceeding the critical value in any one parameter would be sufficient. A dash $(-)$ signifies that the parameter indicated is not considered in a particular case, e.g. for the detection of a sequential change after inferior myocardial infarction, a change of over $30^{\circ}$ in $T_{F}$ or over $70^{\circ}$ in $6 / 8 \mathrm{ST}-\mathrm{T}_{\mathrm{F}}$ is required. The other two parameters are not considered in this particular case. 
for the detection of serial changes using the modified axial lead system. Only ST-T vector parameters were selected as previously indicated. Scalar parameters such as ST junction amplitude were not included for two reasons. First, ST-T amplitude measurements did not exhibit any advantage over the use of vector rotations, except when the $T$ wave changed polarity as discussed below. Secondly, the inclusion of ST junction amplitude into diagnostic criteria was made in a separate fashion, e.g. a reduction in ST elevation from above the upper limit of normal amplitude (not change) to below would be reported by the computer programme as ST improvement. The amount of reduction in amplitude need not be specified.

By using the criteria established in Table 5, it was found that a report of sequential changes could be made for 96 per cent (i.e. 50) of the 52 electrocardiographic series which were regarded by cardiologists as showing a sequential change. In one of the remaining patients, who had an inferior myocardial infarction, the $T$ waves were inverted in lead $\mathrm{Y}$ at the time of the first recording. However, there was initially pronounced ST elevation (in the inferior lead) which diminished during the series so that ST improvement as measured by the computer was apparent. This was regarded as a sequential change. In the remaining patient, who also had an inferior myocardial infarction, the $T$ waves in the inferior lead were upright, but of low amplitude. In a subsequent recording, the $T$ waves exhibited shallow inversion even though the maximum $\mathrm{T}$ vector or $6 / 8 \mathrm{ST}-\mathrm{T}$ vector did not move through a significant number of degrees. This, however, was regarded as a sequential change. Thus, the computer can be programmed to regard a change in polarity of the $T$ wave between successive recordings as a sequential change.

Evidence of myocardial infarction in the anterolateral lead alone was not encountered. It is proposed, however, that the criteria for sequential change after anterolateral myocardial infarction be the same as for anterior myocardial infarction (Table 5), since $T$ vector rotation in the transverse plane would be common to both.

The reason for recording not only day to day change but the change with respect to day $I$ is evident from a study of Fig. 2 which shows a series

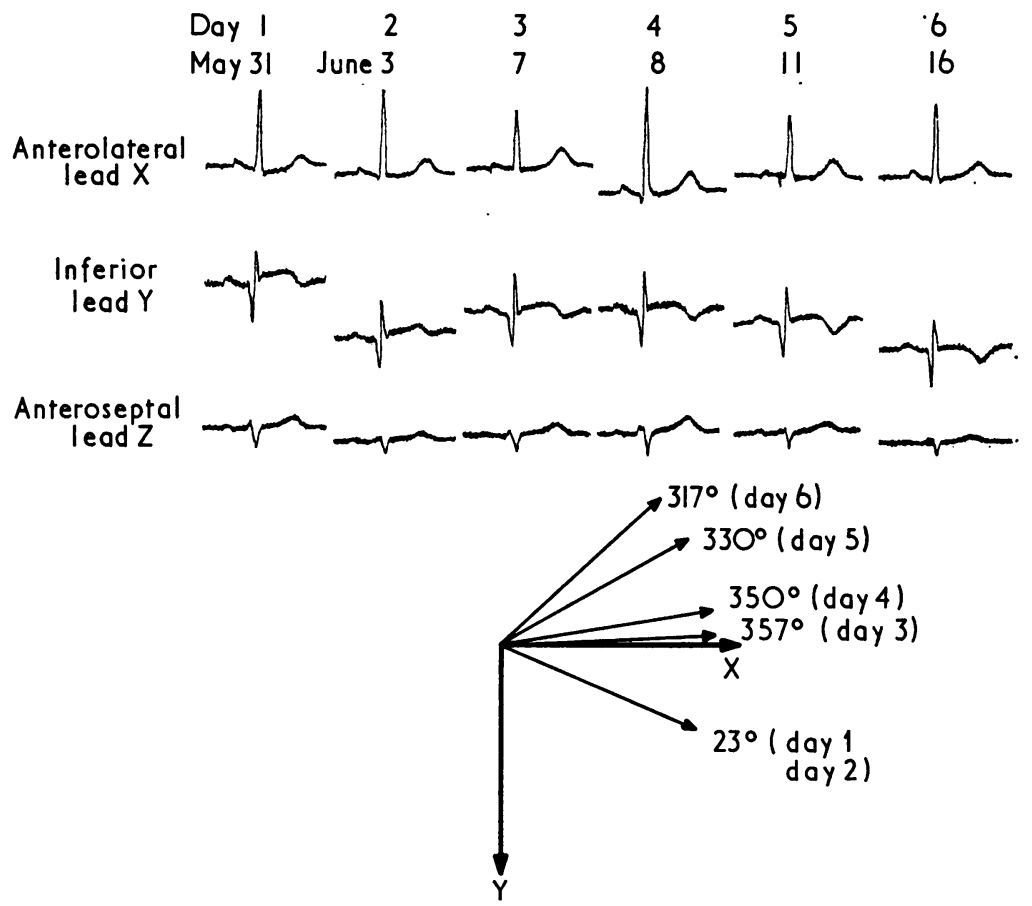

FIG. 2 A series of electrocardiograms recorded from a 48-year-old man. The change in ST-T configuration in the inferior lead $Y$ after myocardial infarction corresponds to a counterclockwise rotation of the projection of the maximum spatial $T$ vector onto the frontal plane as shown in the diagram. 
of electrocardiograms from a patient with inferior myocardial infarction. The day to day change never exceeds the critical value of $30^{\circ}$ whereas the change between day I and day 4 is $33^{\circ}$ enabling the report of sequential change to be made. The remaining tracings from days 5 and 6 confirm the change first detected on day 4 . This type of result influenced the format of storing electrocardiographic interpretations on a computer disc for automated comparison of serial electrocardiograms, as discussed elsewhere (Macfarlane, Cawood, and Lawrie, 1974).

It goes without saying that the mean day to day change was almost always less than the mean change with respect to day I for this series of patients. It should be noted, however, that the latter includes one value common to the former, viz. the change between day I and day 2. Hence, the lower limit of many of the ranges is common to both sets of results.

It is not possible to associate a specific direction in which $T$ vectors rotate for each location of infarction. Fig. 3 shows that the direction of rotation of the $T$ vector is dependent upon the initial conditions. If the $\mathrm{T}$ waves are upright in both the lateral $(\mathrm{X})$ and inferior $(\mathrm{Y})$ leads before the development of $\mathrm{T}$ wave inversion in the inferior lead as a result of inferior myocardial infarction, then the direction of rotation of the $T$ vector is counterclockwise. On the other hand, if the $T$ wave in the lateral lead $X$ is inverted and the $T$ wave in the inferior lead $Y$ is upright before sequential changes ensue in the inferior lead then the direction of rotation is clockwise. A similar consideration applies for anteroseptal or anterior myocardial infarction.

There were 15 patients in the series whose tracings were not regarded as showing a sequential change in the opinion of the panel. With the criteria presented in Table 5, a report of sequential change could not be made.

The results presented in this paper have been incorporated into our computer programme for interpretation of electrocardiograms and have already been tested in extensive clinical use. They are only the first of a set of criteria indicative of sequential change which have been used to date. It is hoped that in due course other criteria for the establishment of sequential change after pulmonary embolism or other cause will also be incorporated.
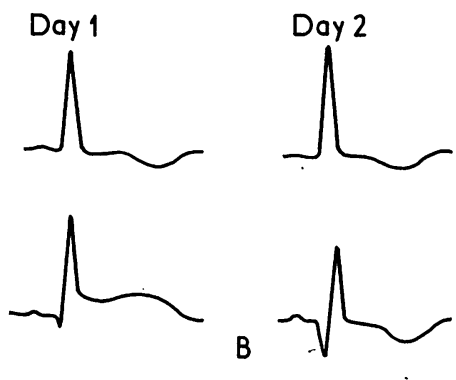<smiles>[R20]C1CCCCC1C</smiles>

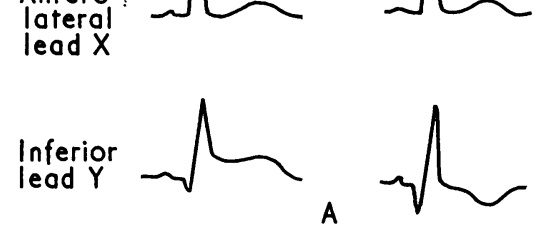
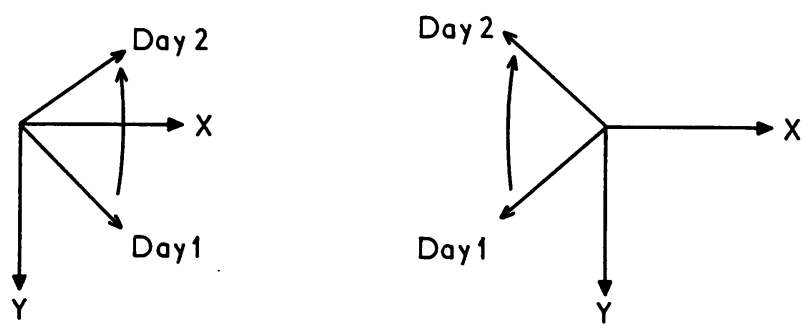

FIG. 3 A) Counterclockwise rotation of the projection of the maximum spatial $T$ vector in the frontal plane. This results from the development of $T$ wave inversion in the inferior lead $Y$ in association with an upright $T$ wave inversion in the anterolateral lead $X . \mathrm{B})$ Clockwise rotation of the projection of the maximum spatial $T$ vector in the frontal plane. This arises from the development of $T$ wave inversion in the inferior lead $Y$ in the presence of an inverted $T$ wave in the anterolateral lead $X$. 
These criteria will rely mainly on the normal limits of day to day variation, as is evident from this paper, but the best diagnostic parameter for each abnormality remains to be selected. It is felt, however, that the present addition to the programme constitutes a significant advance in the technique of automated electrocardiograms of interpretation.

\section{References}

Cawood, H. T., Macfarlane, P. W., Hillis, S., and Lawrie, T. D. V. (1974). Day to day and beat to beat variation in normal 3 orthogonal lead electrocardiograms. British Heart Fournal, 36, 1225.

Downs, T. D., Liebman, J., Agusti, R., and Romberg, H. C. (1966). The statistical treatment of angular data in vectorcardiography. In Proceedings of Long Island fewish Hospital Symposium on Vectorcardiography, New York, p. 272. Ed. by J. Hoffman and R. C. Taymov. NorthHolland Publishing Co., Amsterdam.
Downs, T. D., Liebman, J., and MacKay, W. (I97I). Statistical methods for vectorcardiogram orientations. In Proceedings of the XI International Symposium on Vectorcardiography, New York, p. 216. Ed. by J. Hoffman. North-Holland Publishing Co., Amsterdam.

Macfarlane, P. W. (I969a). A modified axial lead system for orthogonal lead electrocardiography. Cardiovascular $R e$ search, 3, 5 10.

Macfarlane, P. W. (1969b). Computer studies in electrocardiography. Ph.D. Thesis, University of Glasgow.

Macfarlane, P. W. (I97I). ECG waveform identification by digital computer. Cardiovascular Research, 5, I4I.

Macfarlane, P. W., Cawood, H. T., and Lawrie, T. D. V. (1974). A basis for computer interpretation of serial electrocardiograms. Computers and Biomedical Research. In the press.

Macfarlane, P. W., Cawood, H. T., Taylor, T. P., and Lawrie, T. D. V. (1972). Routine automated electrocardiogram interpretation. Bio-Medical Engineering, 7, 176.

Requests for reprints to Dr. P. W. Macfarlane, University Department of Medical Cardiology, Royal Infirmary, 84 Castle Street, Glasgow $\mathrm{G}_{4}$ OSF. 